\title{
Intercultural Education: Bring Together Pluralism and Diversity
}

\author{
By Elvira Martini*
}

\begin{abstract}
Large-scale migrations have forced the creation of new scenarios where the sense of absolute freedom clashes with the search for an ideal community. This situation poses problems related to identity, diversity, the 'discovery of the other' and, therefore, to identifying forms that allow to bring together more and more multi-cultural populations (Benahbib 2002). The aim of this paper is to reflect on the need to consider the educational process as 'methodical socialization' which corresponds to the need for any society to secure the bases of its conditions of existence and of its durability (Filloux 1993). For these reasons the education processes must be based on format with high coefficients of self-reflection, convergence, trans-culturalism. Education, as a social fact, must adapt to change and new alphabets, to overcome the binomial between time to learn / time to work and must insist on creativity and innovation, since everyday life is and it will be increasingly governed by knowledge and, particularly, by the spendable knowledge, a typical feature of complex, cosmopolitan and 'high knowledge claim' societies.
\end{abstract}

Keywords: coexistence, education, inter-culturalism, trans-culturalism, socialization

\section{Introduction}

In the current social context, meeting "the other (the different person from me)" is no longer an event limited to sporadic episodes, but it becomes something that falls within the normal everyday life situations.

However, the migration phenomenon (which in itself represents an opportunity for enrichment) is too often accompanied by media messages that promote fear and suspicion for all diversity, spreading ideas that stigmatize entire populations based on individual behaviour.

It follows that the relative social integration of immigrants is characterized by a significant distance between the latter and the native population. It is clear that this situation poses problems relating to identity, diversity, the discovery of the other and, therefore, to identify forms that allow for coexistence among more multicultural populations.

The shortening of this social distance can be achieved through the creation and experimentation of "spaces" within which to educate young people and adults to "contamination" between different realities, understood as a spirit of sharing, mutual acceptance, constructive exchange and enrichment of values.

\footnotetext{
"Associate Professor of Sociology, Università Telematica “Giustino Fortunato", Italy.
} 
In this process, in addition to the family, educational institutions play a fundamental role, as the first mediators of social inclusion that aims to avoid separation on ethnic, linguistic, religious and cultural bases. Inclusion, cultural and social exchange must be supported by an educational idea that aims at the "recognition not so much of fundamentally equal but rather of irreducibly different from" (Di Nicola 2015: 47).

Therefore the strong idea of an actor involved in social processes emerges; an actor who safeguards the principle of the centrality of the person, also in the educational-training process. The current socio-cultural context and its systemic complexity offers (to the construction of the personality) the possibility of opening up to otherness and exchange but also continuous solicitations for the subject to extend himself to participation and shared responsibility. In this process, the person is perceived as a tension towards the encounter with the other and towards an increasingly extended dialogue (Piu 2015: 8).

Inevitably, all this has an impact on the training systems that, to realize an effective didactics of the dialogue, must necessarily adapt their training proposal, building innovative and creative didactic paths that are transcultural. A didactics understood as mediation, dialogue, relationship, interactivity, reflexivity, able to contribute to the formation of cognitive autonomies ready for dialogue, cooperation, understanding the indispensability of the other.

\section{Recognize Oneself in a Complex and Transcultural Society}

The era in which we live can be defined as the era of differences and uncertainty: individual, territorial and cultural differences, which postulate the meeting between peoples and civilizations and for which the keywords become multicultural, intercultural, trans-cultural (Piu and Pitto 1993).

In other words, the phenomenon of complex society places political, sociological, and even pedagogical attention on the concept of social inclusion, not so much based on the principle of equality as on that of egalitarian difference (Benahbib 2002), a principle that postulates the 'participatory and meaningful inclusion within a community, actively contributing to its development and its economic and political growth. But even more to the concept of integration, understood as the need for recognition of the self and of the claim of one's cultural identity. And starting from the current socio-cultural scenario -which inevitably suffers the effects of globalization and cosmopolitanism as well as that which Giddens (1990) calls the second modernity- that the struggles for recognition live a renewed season, precisely because the emergence of particular political, social and cultural conditions have made the systems incapable of accepting and including within them the different units (Di Nicola 2015: 47).

In fact, despite the myth of globalization (Cesareo and Magatti 2000), which would tend inexorably towards the unification of the world, we find ourselves faced with a ubiquitous patchwork: global processes do not tend naturally towards unity or 'uniformity, but on the contrary, if left to themselves, they help to remove the ideal of the community, producing instead strong imbalances, inequalities, 
exclusions that select (and not only symbolically) who should be kept out and who can be included. We are witnessing an ambivalence between forms of exclusionary inclusion and softer forms, although not entirely definitive, of selective inclusion and therefore to "an ambivalence that creates differentiations and grades the levels of inclusion and marginalization" (Tucci 2018: 57) ${ }^{1}$.

However, in this situation it is justified that the demand for a liveable community among men and women becomes more and more pressing, although it seems that we should be satisfied only with community surrogates, as the communities no longer present themselves as a natural fact. And unlike natural communities, these surrogates fail to resolve the dichotomy of freedom/security, rather they sharpen it: "if it is true that the community gives security, it requires a certain sacrifice of freedom" (Bauman 2001: 6). Modern individualism makes us increasingly insecure, because it offers (and not to all) freedom in exchange for security. And the vulnerability of individual identities leads to the search for "crutch-communities, on which people hang their worries, otherwise experienced individually" (Bauman 2001: 17).

The need to rediscover a space-centric unity is accompanied by what Hobsbawm and Ranger (2002) call the invention of tradition, a possible response to rapid social change, a need to establish continuity with the past, through social and ritual practices that ensure socialization and social cohesion.

However, it is precisely the return to tradition that lends itself to an inevitable pitfall: continuing to consider the community as a place of homologation and identity and not rather as a place of contamination between local and global, between equal and different, of the conviviality of differences (Nanni and Weldemariam 1994). In this sense, then, the community would be invented to exorcise the fear and neutralize the danger, by joining together (Berti 2005: 68).

This "narrow and silent" vision of community highlights all its limitations when the fear of the other is read as fear towards the foreigner: "not being together but avoidance and being separated have become the main strategies for survive in contemporary megalopolises" (Bauman 1999: 55).

According to Bauman, even the new cosmopolitans feel the need for "community", only that, obviously, they tend to recreate flexible and "timed" communities, which can be easily dismantled and that only leverage on their dreams and desires. This means an unbridled search for a safe and overprotected social environment, and the community becomes the favourite tool of those who believe that "identity" only means exclusion of the other as different. Therefore the "safe community" becomes a "voluntary ghetto". All this increases the selfperpetuating mechanisms of segregation and exclusion.

It is very probable that 'identity-ism' (this great identity myth) is actually a defence strategy for our privileges. But it is a short-sighted strategy that fosters

\footnotetext{
${ }^{1}$ On the issue of inclusion, or rather expulsion, Saskia Sassen also expressed, whose sociological analysis was conducted in support of the thesis that the expulsions would represent the result of predatory formations that are expressed in "decisions and actions that have their own weight, but that are part of large assemblages of elements, conditions and dynamics that mutually reinforce each other" (2015: 88).
} 
conflict: people who use this strategy do not know how to see any other solution than their own privileges and advantages. Beyond the "we" there are only enemies (Remotti 2011, 2017).

The search for a safe space underlines the importance of the emotional dimension of globalization. The 'indicators of self-confidence', as Moïsi calls them (2009: 22) scientifically measure the level of trust of a population in their future, the ability to know how to use their skills and even transcend them. And the level of self-confidence is well expressed by three primary emotions: fear, hope and humiliation (Moïsi 2009: 22). The rediscovery of emotions is necessary where states, like those in the West, can no longer rely on historical ideals or economies that have become too evanescent; in these scenarios, therefore, an attitude of bitterness and a desire to protect oneself from hostile forces is born. "But the main reason why today's globalized world is a fertile ground for growing emotions is that globalization produces insecurity and raises the question of identity. [...] Identity is closely linked to self-assurance and in turn self-confidence, or its absence, is expressed in emotions, particularly in fear, hope and humiliation" (Moïsi 2009: 29). The myth of identity arises in a context of globalization, in which relations between countries and cultures have become increasingly dense and increasingly risky and conflicting. Remotti defines it as the "product of cultural impoverishment; [...]. Because of identity, we see only what threatens us in relationships with others, and this is a huge cultural poverty. In this context, the myth of identity also combines with fear: the fear of losing one's things, one's privileges, one's substances; the great fear of having to share. We therefore cling to identity as something that illusively gives us security: an illusory security, a fallacious and dangerous myth" (Remotti 2011, 2017). Although the key to understanding others is the intertwining of these emotions, emotions very often generate that emotional discomfort that can arouse situations of non-recognition of the face of the other and indifference.

This is what happens when those who cross the border become for us a "radically different", not attributable to our world and towards which it is very difficult to activate the ethical action of solicitude (Ricoeur 1997).

All this means that the construction of multiple identities (individual and social) is shown as a difficult and high-risk process, especially when the need for roots and rooting exacerbates the differences, heightening individualism and insecurity. That same insecurity that the individual suffers in the era of globalization and that generates the absence of community. "When the community collapses, the notion of identity is invented" (Young 1999: 164). And identity means getting out of the deck, it means being different and, as such, unique; and therefore the search for identity can only divide and separate. However, the vulnerability of individual identities leads to the search for "crutch-communities", on which people hang their concerns together, otherwise experienced individually (Bauman 2001: 17).

In this sense, acceptance assumes the meaning of interaction, relationship, inter-subjectivity. And as such it is the result of the ego-alter dialectic, of the meeting of two diversities that at the moment of mutual recognition do not get confused and do not merge but are constituted autonomously by difference 
(Bauman 2001: 49). Recognizing and accepting becomes all the more necessary the more the social becomes fragmented and multiplies in spheres of reality that encompass levels of knowledge of common sense and as such feed the processes of reflexivity in the construction of personal identities that can only be, therefore, multiple and plurals (Di Nicola 2002). Consequently, also culture, understood as an institutionalized form of knowledge, is fragmented and distributed in a multiplicity of 'divergent worlds' (Di Nicola 2002: 49), losing part of its performance capacity of individual behaviour and becoming a process of learning, reorganization of cognitive maps and re-orientation to action (Bauman 1999).

Therefore, the migratory universe brings to a new conception of culture that can be defined, precisely, as trans-culturality (Welsch 1999) and that contributes even more to strengthening the paradigm of the formation of multiple identity.

Multiculturalism (understood as the coexistence of different cultures) and its direct development, inter-culturality, have revealed their limitations over time, as they are rooted in a traditional conception of culture that maintains a marked insistence on 'difference', on the sense of "otherness" in the contact between cultures. And where emphasis is placed on the differences between groups, there is a risk of creating even more distance between them and one can even, without intending it, initiate segregation and ghettoization processes. Cultural barriers remain and one can incur reaffirmation and reinforcement of stereotypes. Moreover, the process of recognition and valorisation of otherness can lead to vain and often harmful essentialisms and to an exasperated idealization of the culture or country of origin (Tumino 2011: 603). Amselle (2007: 81) would say "the métissage would be perceived as an invasion syndrome, so any overcoming of barriers, any encroachment in the other territory would turn into a real concern for the creation of bastardise situations (bastardization)". Therefore, despite good intentions, inter-culturality could produce perverse effects and lead to cultural or even 'racist' fundamentalists.

It is clear that this concept is inadequate compared to the multiplicity of cultural inter-connections (increasingly dense and complex) typical of globalization and trans-nationalization. "In a multicultural context that involves meetings, conflicts and contaminations between people, peoples and cultures are multiplied and the closed conception of cultural systems is unattainable, today. In fact, they have always been fed by hybridizations and exchanges" (Tumino 2011: 604).

To explain the processes of formation of these new, modern and multiple cultural forms, new conceptualizations and models of cultural interaction are therefore necessary. The concept of trans-culturalism, precisely, responds exactly to this need.

Welsch, in this regard, puts the emphasis in cultural fertilization at multiple levels, from the macro-level of societies - whose cultural forms are characterized by internal differentiation, complexity and hybridization - to the micro-level of individual experience, where personal and cultural identity almost never corresponds to the civic and national one and it is instead increasingly marked by multiple cultural connections. From the pragmatic point of view, the traditional concept of cultures as discrete units (which, placing the emphasis on what is 
proper to a people and the exclusion of everything that is different and foreign, tends irremediably to a sort of cultural racism) is overcome by trans-culturality which aims, instead, at an intersected and inclusive vision of culture: It intends a culture and society whose pragmatic feats exist not only in delimitation, but in the ability to link and undergo transition (Welsch 1999: 200). Therefore, transculturality must be understood not only as a model of analysis of modern reality, but also as an ideal to which to tend in the daily practice of cultural interaction: It is a matter of readjusting our inner compass: away from the concentration on the polarity of the own and the foreign to an attentiveness for what might be common and connective wherever we encounter things foreign (Welsch 1999: 200).

Where trans-culturality becomes the analytical model for reading today's cultural reality, trans-culturalism could be a more suitable term to designate a will to interact -starting from intersections rather than differences and polarities-, the awareness that in all people there is a trans-cultural dimension, which helps us to better understand and welcome what is outside of us, a vision that favours flexibility, movement and continuous exchange, the continuous renegotiation of identity (Tumino 2011: 607-608).

Behind the Borders: Safer or More Isolated?

The matter of the border stands as the matter of the space to occupy (Martini and Vespasiano 2016: 82-84).

"The important thing in order to claim any right within an unlimited space is to enter it, to settle there, to sneak inside, taking possession of an area of interest, to occupy an area that, each time, may be social, political, sexual, mental and economic. Only after occupying this space, if you want, you can trace the outline, close it within a boundary and delimit it. The experience of the border starts, therefore, always from the inside" (Zanini 1997: 30-31). Therefore, "it is hard to think that someone belongs to something (to a community, a political organization) without imagining, at the same time, a policy of separation, the definition of boundaries (Costa 1999: 43). It is, therefore, the function that the border plays in defining an "inside" and "outside", with respect to the reference community, to give it the character of "establishment of institutions" (Balibar 2010: 315).

According to an interesting perspective on the origin of the concept of border it can be understood as: limen or limes (Cacciari 2000: 73-79). Limen is the threshold, the pass through which one enters a domain or comes out of it and limes is, instead, the path that surrounds a territory, which contains its form.

Based on this etymological suggestion, Gomarasca supposes a boundary model organized according to two fundamental theses. "The first thesis (T1) concerns the structure of the border, its essential duality: there is no boundary that is not limen and limes together. In fact, the border is never rigid. It indicates the line along which the two men are touching (cum-finis) ${ }^{2}$. The second argument

\footnotetext{
${ }^{2}$ Simmel's picture of the frame metaphorically describes very well this thesis: "for the social group,
} 
(T2) concerns the writing of the border: we can live (and therefore build) a space only if we draw boundaries. Here, above all, the anthropological significance of the concept is at stake: each of us constantly establishes borders while acting and interpreting the world (Mezzadra 2000: 149). In other words, men are beings who produce, wherever they live, guarded spaces" (Gomarasca 2004: 18).

The correlation of these two theses leads us to affirm that the boundary makes distinctions while uniting and therefore "no border can eliminate or leave out another one, because it implies it in its very being" (Gomarasca 2004: 19). However, only rarely it happens that solidarity mechanisms activate processes of concern to the other; in most cases it is the opposite to occur, with episodes of hostility, fear and indifference, evoking ethnocentrism as a universal feature of human groups. "A natural consequence related to the construction of the border is to throw out from the area that has been created s/he-what is considered as an intruder. Exclusion leads someone or something to the edge of an area, away from the centre: this is where the outcast is (Geremek 2012: 391-421). And sometimes this can also be pushed over the border until it becomes a foreigner, that is something other than what you want to contain within the boundary" (Zanini 1997: 55).

This attitude towards the other has a strong correlation with the social structure and cultural environment. "The attitude towards the foreigner depends on the way of feeling and being of the community, social groups and individuals. The individual and, above all, the community identity, determines the attitudes and strategies of action" (Cotesta 2002: 5). In other words, the exclusion mechanism arises from the inability to be able to classify, by their own cultural categories, the peripheral elements, seen as deviant, dangerous anyway. This is how "the stranger becomes someone who is not a member of our own field from the beginning; then when s/he gets there, s/he imports a set of special features, qualities, which, in the long run, can modify, more or less in depth, its character" (Zanini 1997: 60).

The stranger disrupts the familiarity of the space of belonging and requires, in any case, to rearrange this space and to revise the limits ${ }^{3}$. This reorganization depends on the ability to integrate other individuals in own environment; when there is no such ability, we add a little self- confidence, then we tend to assume basically suspicious and hostile attitudes" (Simmel 1989: 580).

In short, "on the border and across the border differences are structured: the symbolic, the legal and the political ones. Differences having other differences, between those who have rights and those without; between those who belong to a particular community and those who are excluded" (Nuzzo 2006: 129). Thus, the boundary builds its own citizens according to approval and uniformity criteria

the frame assumes a function very similar to that which it has for a work of art. In this one it exerts the two functions, which are exactly the two aspects of a single function: to mark the boundary of the work of art as to the surrounding environment and to close it in itself' (Simmel 1989: 529).

${ }^{3}$ Being a foreigner, for Simmel, means that "the distant subject is near" (1989: 582) and that the difference is close to our environments and insists to enter and remain there; the stranger is not exactly "the traveller who today comes and tomorrow goes, but [...] the one who today comes, and tomorrow stays - so to say the potential traveller who, not having continued to move, has not entirely overcome the absence of ties of going and coming" (Simmel 1989: 580). 
(inward), becoming a "necessary condition and, at the same time, 'non-democratic' of democracy" (Rigo 2015: 10-14).

\section{Educational Process as 'Methodical Socialization'}

The purpose of this work is to reflect on what attitudes to assume, moving from the culture of individualism (typical of the dominant culture) to the culture of partnership, which is based on dialogue and cooperation. The cultural model of individualism characterizes the educational systems of many countries where the problems related to globalization and awareness of current realities are not considered relevant to national programs, while the partnership model favours international cooperation between nations and peoples (North-South Centre of the Council of Europe 2012: 13).

Therefore, we need to identify ways that allow the coexistence of more and more culturally heterogeneous populations, indicating methods and rules that govern this cohabitation within the same social configuration.

In this situational framework, we ask ourselves about the need for a new educational model with a high coefficient of convergence and unity, as well as on the elaboration and experimentation of real integrated curricula, that respond to the needs of transcultural communication. Delors (1996), clarifying the objectives of education, recognizes that one of the fundamentals of knowledge is undoubtedly the ability to know how to build meaningful relationships with others, so as to identify in the expression 'learning to live together' one of the highest goals of every training system.

This is because considerable importance is given to the ability of each subject to be able to cooperate and collaborate constructively with others without distinction of sex, religion, ethnicity, culture or values (Piu 2015: 7).

Transformative learning generates a profound and structural change in the premises of thought, feelings and actions, through intercultural education. This education of mind and heart is followed by a radical change that goes towards interconnection and the adoption of all the instruments to guarantee greater equity, social justice, understanding and cooperation between peoples.

Intercultural education as transformative learning leads to participatory decision processes at all levels. The objective of this type of learning consists in strengthening mutual knowledge and the collective awareness of oneself (NorthSouth Centre of the Council of Europe 2012: 14).

With the shift of attention to the transformation from a culture of reproduction and domination to a partnership based on dialogue and cooperation, intercultural education modifies the rules established by the global economy, bringing human dignity back to a central value.

In an interesting article (1911), entitled 'Education, its Nature and Role' published in Education et sociologie, Durkheim asserts, on the basis of 'historical observation', that 'every society, considered at a given moment in its development, has a system of education which is imposed on individuals". Every society sets itself a certain 'human ideal', an ideal of what a person should be from the 
intellectual, physical and moral points of view; this ideal is the crux of education. Society can subsist "only if there is sufficient homogeneity among its members". Through education, the 'individual being' is turned into a 'social being'. [...] "It emerges from the foregoing definition that education consists of a methodical socialization of the young generation" (Durkheim 1992: 51).

This view of education as 'methodical socialization' corresponds to the need for any society to secure the bases of its 'conditions of existence' and of its durability (Filloux 1993: 3).

The definition proposed above, however, merely describes the 'fact' or essential nature of education at a given moment, from a static point of view. However, not only do societies 'change', evolve and have a history, but within those societies themselves, the institutionalized education systems that are consistent with their needs also evolve and, in turn, generate their own needs. The 'science of education' as the objective study of the social fact of 'education' must consequently situate these systems in the context of a general dynamic which can in fact be described by analysing it in terms of stages in social reality (Filloux 1993: 3$)^{4}$.

For these reasons, otherness acquires a meaning and a value that must necessarily overcome the simple tolerance of the different or its cultural assimilation; therefore, it becomes very difficult to set up a cross-cultural policy, since each of us has a tendency to conform to the conventions and convictions of the ethnic group of belonging, without worrying about the partiality or the limitation of one's own point of view.

A cultural revolution that brings the different, the foreigner that makes him/ her know and "feel" close must be postulated, as indispensable and necessary. A cultural revolution that rationalizes atavistic fears, unconscious aggressiveness and difficulties through dialogue, rapprochement and cohabitation (Cambi 1993).

So, education (this process of methodical socialization) is the preferential path to socio-cultural integration. This is true when it focuses on three central aspects: the quality of the training provided, the 'global needs' of immigrants and the projects of migrants and their families (Fiorucci 2007). "Training, for the immigrant, is a summary of reception and stabilization. The immigrant agrees to undertake an educational path both to coexist in the ambiguity of his condition and to get out of it. He begins a process of linguistic, socio-cultural and professional re-identification because he knows that he can no longer bear to live only with the 'gift-refuge' represented by his own language, mentality, and operativeness. The immigrant seeks the security that the contents of the training can give him (from the first literacy to professional training)" (Demetrio and Favaro 1992: 33).

\footnotetext{
${ }^{4}$ Let us consider the main thrust of the durkheimian model. Central to it is the concept of conscience collective. A society is composed of individuals who 'cohere' because they share common values and rules, partly transmitted by school. Society, as an object constructed by sociology, has its own specific nature defined by the parameters of 'integration' (allegiance to the group) and 'regulation' (recognition of rules controlling individual behavior). This conscience collective is reflected in collective phenomena ranging from the strictly mental level of collective representations to the level of 'institutions' and that of a 'material substrate' (volume and density of population, communications, buildings, etc.) (Filloux 1993: 4).
} 
Training alone cannot solve all the problems of integration of migrants: the outcome of the integration paths also depends on the more complex integration policies that a country is willing to implement. Integration policies that, without neglecting the primary needs, must overcome the emergency approach that tended to consider immigration not as a structural phenomenon but as a contingent phenomenon (Fiorucci 2007).

If this happens, training can become a preferential way to integrate immigrants into the economic, social and cultural context of the host countries: "we must learn to recognize in each stranger a person who brings with him a history and a memory, which has a culture and a homeland, a life project, skills to enhance and things to say; that he meets different and differently acute problems according to the ethnic group, from his being a man or a woman, young or old; which has not only needs for food or lodging, but also for communication, sociability, affection and culture. It is about looking at the facts with a new representation and, therefore, doing a cognitive renovation. This is indispensable if we want to send to foreigners the new and different image we must have of them" (Susi 1991: 20).

\section{Conclusions}

The different ways of delivering knowledge (presence, at a distance, blended learning) must adapt to the changing needs of the knowledge and skills society and be linked to a concept of culture that makes pluralism and difference live together.

To do this, three fundamental acquisitions are necessary, in order to ensure adequate intercultural and transcultural training processes:

1. to leave the 'myth of the emergency' to assume cultural diversity as the school paradigm, which requires a 'continuous and structural' intercultural planning (and not a 'temporary and special' project);

2. the presence of foreign students represents "a precious opportunity to rethink their educational, didactic, relational and organizational models and to challenge them";

3. intercultural education ${ }^{5}$ is one of the elements of the anthropological renewal process ${ }^{6}$ of the theory and practice of education that is "necessary

\footnotetext{
${ }^{5}$ Intercultural education is a generic expression that refers to the pedagogical concepts related to the realities of today's world. It is therefore an open, evolving and multidimensional concept of contemporary general education. Furthermore, it is considered a holistic collective response to the historical challenge, consisting in helping active global citizens, to create and recreate a different world, more equitable, fairer, more peaceful, more sustainable, based on international solidarity (North-South Centre of the Council of Europe 2012: 20).

${ }^{6}$ On several sides, we insist on the importance of teaching anthropology in schools of all levels. It is of fundamental importance to get the discipline out of its specialized horizons and make it a knowledge for everyone: a discipline capable of dialoguing not only with other disciplines, but also with all those professional figures who play some educational and training role. Anthropology is also a way to preserve the exercise of critical autonomy and to guarantee democratic but also critical and conscious action, both inside and outside the classroom. Children must live in an environment that educates them to pluralism, where they are taught that there is a different thought than the
} 
for everyone, for the new generations, for whom a good multilingualism education affects the future of all young people, where curiosity and openness to different cultural forms are not welcome gestures but important skills to face the world of work" (Pastori 2010: 191-192).

Intercultural education allows individuals to develop their knowledge and skills, to adopt values and aptitudes suitable for building a just and sustainable world in which all individuals have the right to exploit their potential.

Figure 1. The Dimensions of the Intercultural Education Process
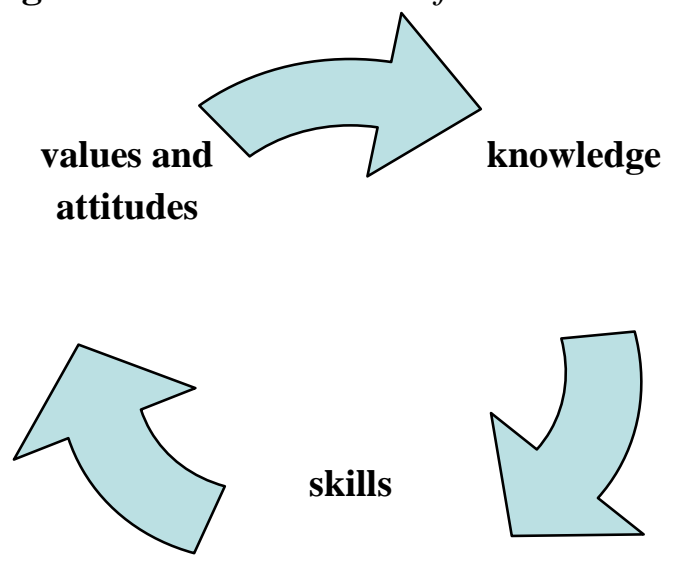

skills

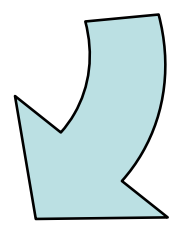

Source: Our calculation by North-South Centre of the Council of Europe 2012: 20

Consequently, in the learning process of intercultural education, students and educators deepen their reflections on the roots and causes of events and developments and share ideas on possible solutions, within the framework of a dynamic exercise of observation, analysis, reflection and exchange of information that generates a new field of knowledge and interests. Differences in sex and social class, as well as ethnic, religious, socio-economic and cultural differences faced during the dialogues, will be part of the questions and problems discussed and possible solutions adopted. Within the framework of this process, knowing refers to everyday knowledge, to the vision of life and all its aspects through a local and global prism, to an interconnected and interdependent approach, aimed at reenergizing the learning process and making the external world become an integral part of the analysis of daily life (North-South Centre of the Council of Europe 2012: 21).

This means that in education and training processes there are essentially three tasks, particularly complex and delicate:

1. the enhancement of differences to allow going beyond cooperative relationships and recreating symbolic channels capable of conveying universally shared values; 
2. the creation of a profound intercultural ideal tension to achieve effective goals of democracy and new forms of solidarity and non-homogeneous coexistence;

3. the promotion of a proper capacity to succeed in resolving conflicts, in order to generate relationships capable of characterizing the context of relationships as a generative peace environment (Piu 2015: 9).

So the key words become difference cohabitation, relationality, connection and they are understood as universally shared values and as current and poietic educational instants, the only ones able to ensure the transition from an ethnocentric orientation (negation, defence, minimization) to an ethno-relative one (acceptance, adaptation, integration) (Hammer et al. 2003).

Therefore, education as a social fact must adapt to change, to new alphabets, to overcome the binomial time to learn / time to work and must insist on creativity and innovation, since everyday life is and it will be increasingly governed by knowledge and, particularly, by expendable knowing, a typical feature of complex, cosmopolitan and 'high knowledge claim' societies.

\section{References}

Amselle J-L (2001) Connessioni. Antropologia dell'universalità delle culture. Torino: Bollati Boringhieri,

Amselle J-L (2007) Dal métissage alla connessione. In La società di tutti, F Pompeo, (ed). Multiculturalismo e politiche dell'identità. Roma: Meltemi.

Balibar É (2010) At the borders of citizenship: A Democracy in Translation?. European Journal of Social Theory 13(3): 315-322.

Bauman Z (1999) La società dell'incertezza. Bologna: il Mulino.

Bauman Z (2001) Voglia di comunità. Roma-Bari: Editori Laterza.

Benahbib S (2002) The Claims of Culture. Equality and Diversity in the Global Era. Princeton University Press. Princeton.

Berti F (2005) Per una sociologia della comunità. Milano: FrancoAngeli.

Cacciari M (2000) Nomi di luogo: confine. In "Aut aut," vol. 299-300, 73-79.

Cambi F (1993) Il dialogo tra uomini. In Multiculturalità e integrazione delle etnie, C Piu, C Pitto, (eds). Nuovo Albero e Elica. monografico, 3-4.

Cesareo V, Magatti M (eds) (2000) Le dimensioni della globalizzazione. Milano: Franco Angeli.

Costa P (1999) Civitas. Storia della cittadinanza in Europa, vol. 1: Dalla civiltà comunale al Settecento. Roma-Bari: Laterza.

Cotesta V (2002) Lo straniero. Pluralismo culturale e immagini dell'Altro nella società globale. Roma-Bari: Laterza.

Delors J (1996) Nell'educazione un tesoro. Roma: Armando.

Demetrio D, Favaro G (1992) Immigrazione e pedagogia interculturale. Bambini, adulti, comunità nel percorso di integrazione. Firenze: La Nuova Italia.

Di Nicola P (2002) Amichevolmente parlando. La costruzione di relazioni sociali in una società di legami deboli. Milano: Franco Angeli.

Di Nicola P (2015) Riconoscimento e rispetto: la dialettica ego-alter nella società della diversità. In Sociologia Italiana, 6: 43-60.

Durkheim E (1992) Education et sociologie. Paris: Press Universitaires de France. (ed. or 
1911).

Filloux J-C (1993) Emile Durkheim (1858-1917). In Prospect: the quarterly review of comparative education. 23(1/2): 303-320.

Fiorucci M (2007) Formazione e immigrazione, LLL (Focus on Lifelong Lifewide Learning. Anno 2, n. 8. Retrieved from https://bit.ly/3aQmLQL.

Geremek B (2012) L'emarginato. In L'uomo medioevale, J Le Goff (ed), 391-421. Laterza. Roma-Bari.

Giddens A (1990) The Consequences of Modernity. Cambridge: Polity Press.

Gomarasca P (2004) I confini dell'altro. Etica dello spazio multiculturale. Milano: Vita e pensiero.

Hammer MR, Bennet MJ, Wiseman R (2003) Measuring intercultural sensitivity: The intercultural development inventory. International Journal of Intercultural Relations 27(4): 421-443.

Hobsbawm EJ, Ranger TO (2002) L'invenzione della tradizione. Torino: Einaudi.

Martini E, Vespasiano F (2016) To re-educate oneself to citizenship within the cultural pluralism. Journal of Mediterranean Knowledge-JMK 1(1): 79-90.

Mezzadra S (2000) Cittadini della frontiera e confini della cittadinanza. Per una lettura politica delle migrazioni contemporanee. In "Aut aut" vol. 298, 133-153.

Moïsi D (2009) Geopolitica delle emozioni. Le culture della paura, dell'umiliazione e della speranza stanno cambiando il mondo. Milano: Garzanti Libri.

Nanni A, Weldemariam H (1994) Stranieri come noi. Dal pregiudizio all'interculturalità. Bologna: EMI.

North-South Centre of the Council of Europe (2012) Global Education Guidelines. Lisbona.

Nuzzo L (2006) Cittadinanza: Un percorso di lettura. In Rechtsgeschichte 8: 129-147.

Pastori G (2010) Nello sguardo dell'altro. Pedagogia interculturale e identità. Milano: Guerini.

Piu C (2015) Complex society and education [Società complesse e formazione]. In $Q$ Times Webmagazine. VII(2). Retrieved from http://www.qtimes.it.

Piu C, Pitto C (eds) (1993) Multiculturalità e integrazione delle etnie. Nuovo Albero a Elica, monografico.

Remotti F (2011) L'ossessione identitaria. In Rivista Italiana di Gruppoanalisi. XXV, 1, 9-29. Retrieved from https://bit.ly/2RVneID.

Remotti F (2017) L'ossessione identitaria. Roma-Bari: Laterza.

Ricoeur P (1997) La persona. Brescia: Morcelliana.

Rigo E (2015) Confini e cittadinanze. In Rivista di Storia delle Idee 4(2): 10-14.

Simmel G (1989) Sociologia. Milano: Edizioni di Comunità.

Sassen S (2015) Espulsioni. Brutalità e complessità nell'economia globale. Bologna: il Mulino..

Susi F (1991) I bisogni formativi e culturali degli immigrati stranieri, La ricerca-azione come metodologia educativa. Milano: Franco Angeli.

Tucci A (2018) Dispositivi della normatività. Torino: Giappichelli Editore.

Tumino R (2011) Transculturalità e trans-culturaliismo: una nuova (?) frontiera della ricerca pedagogica. Aracne. Roma. Retrieved from https://bit.ly/3aKMBWl.

Welsch W (1999) Trans-culturality: The puzzling form of cultures today. In Spaces of Culture: City, Nation, World, M Featherstone, S Lash (ed), 194-213.

Young J (1999) The Exclusive Society. Crime and Difference in Late Modernity. London/Thousand Oaks: Sage Publications.

Zanini P (1997) Significati del confine. I limiti naturali, storici, mentali. Milano: Bruno Mondadori. 
